\title{
Práticas e protocolos comunicativos na deliberação de políticas públicas de saúde: um estudo da comunicação no processo decisório em um conselho deliberativo
}

\author{
Practices and communicative protocols in the deliberation of public \\ health policies: a study of the communication in the decision-making \\ process in a deliberative council \\ Prácticas y protocolos comunicativos en la determinación de las políticas \\ públicas de salud: un estudio de la comunicación en el proceso de la \\ toma de decisiones en un consejo deliberante
}

Antonio Sardinha | sardinhajor@yahoo.com.br

Programa de Pós-Graduação em Comunicação da Universidade Estadual Paulista Júlio de Mesquita Filho (UNESP)

\section{Resumo}

O artigo apresenta resultados de investigação envolvendo a natureza e a dinâmica dos fluxos de informação e o modelo de comunicação no processo deliberativo da política pública de saúde no Brasil. Por meio de estudo de caso de um conselho gestor de saúde local, destacamos práticas de um modelo vertical na organização de fluxos de informação e comunicação que desconsidera o papel da informação na deliberação da política de saúde.

Palavras-chave: comunicação pública; deliberação; políticas públicas de saúde; Brasil; estudo de caso. 


\section{Abstract}

The article presents research results involving the nature and dynamics of the flows of information and the communication model in the deliberative process of the public health policy in Brazil. Through case study of a local health management council, we highlight practices of a vertical model in the organization of information and communication flows that ignores the role of the information in the health policy deliberations.

Keywords: public communication; deliberations; public health policies; Brazil; case study.

\section{Resumen}

El artículo presenta resultados de investigación envolviendo la naturaleza y la dinámica de los flujos de información y el modelo de comunicación en el proceso de deliberación de la política de salud pública en Brasil. A través de estudio de caso de un consejo de administración de salud local, se destacan las prácticas de un modelo vertical en la organización de los flujos de información y comunicación que desconsidera el papel de la información en la deliberación de la política de salud.

Palabras clave: comunicación pública; deliberación; políticas pública de la salud; Brasil; estudio de caso.

Contribuição dos autores: o autor é responsável por todo o artigo.

Declaração de conflito de interesses: não há conflito de interesse

Fontes de financiamento: Fundação de Amparo à Pesquisa do Estado de São Paulo (FAPESP)

Considerações éticas: Normas éticas foram seguidas

Agradecimento/Contribuições adicionais: não há

Histórico do artigo: Submetido: 07.jan.2017 | Aceito: 05.jun.2017 | Publicado: 29.set.2017

Apresentação anterior: $O$ artigo é parte de pesquisa desenvolvida no mestrado em Comunicação (PPGCOM- UNESP) Licença CC BY-NC atribuição não comercial. Com essa licença é permitido acessar, baixar (download), copiar, imprimir, compartilhar, reutilizar e distribuir os artigos, desde que para uso não comercial e com a citação da fonte, conferindo os devidos créditos de autoria e menção à Reciis. Nesses casos, nenhuma permissão é necessária por parte dos autores ou dos editores. 


\section{Introdução}

Neste artigo, sistematizamos parte de resultados obtidos em pesquisa ${ }^{1}$ e procuramos mapear e compreender a dinâmica e natureza dos fluxos de informação e o modelo de comunicação que circunda uma esfera pública especializada como a dos conselhos de saúdei. De acordo com Raichellis², a democratização desses espaços de controle social da política de saúde implica observar a dialética entre conflitos e consensos, de maneira que os diferentes e múltiplos interesses possam ser qualificados e confrontados, resultando na interlocução pública capaz de gerar acordos e entendimentos que orientem decisões coletivas, nesse caso, sobre a política de saúde.

Sob esse viés, entendemos serem campos privilegiados de observação e investigações em comunicação e saúde: as dimensões, escopos, práticas, protocolos e delineamentos gerais das ações de comunicação no controle social da política de saúde, em que pese a relação estruturante da informação e comunicação com as três dimensões estruturais da democratização do processo decisório das políticas públicas sugeridas pelos estudos sobre participação e políticas públicas: (1) a representatividade e pluralidade dos atores envolvidos na deliberação; (2) o poder de acessar, interferir e deliberar na esfera pública decisória; e (3) o poder de inclusão de temas estruturantes na agenda de deliberação local ${ }^{3}$.

\section{Apontamentos teórico-metodológicos}

Entendemos o conselho de saúde como um espaço político poroso e aberto, por sua formação democrática e seu caráter decisório sobre a política de saúde, que é permeado por esferas públicas (de discussão) e espaços sociais (de circulação), seguindo a lógica de existência de redes de sujeitos políticos, descentralizados e entrelaçados nos seus espaços sociais de produção de sentido (movimentos, partidos, sindicatos, governos), conforme a configuração de Pitta. ${ }^{4-5} \mathrm{O}$ foco na comunicação pública está na compreensão da sua relação intrínseca com a democracia pela possibilidade de instituir um continuum, um dado padrão de conflitualidade na esfera pública e assim um dado modelo de democracia ${ }^{5}$. A partir do entendimento de Monteiro ${ }^{6}$, com base em Wolton7, entendemos que o locus da comunicação pública é o espaço simbolicamente organizado em um padrão/modelo de comunicação entre o Estado e a sociedade, constituído por um espaço político (decisão), outros espaços públicos (discussão) e um espaço social (circulação). ${ }^{6}$ É do fluxo de informação e comunicação - que permeiam essas três esferas - que teoricamente a comunicação pública deve se ocupar. Como política pública sistematizada e organizada, ela pode se ocupar da gestão informativa de discursos, dados e conhecimentos que circulam entre as três esferas e sustentar a deliberação de políticas públicas nos espaços decisórios dos conselhos gestores de saúde.

Com base no modelo ${ }^{8}$ que adotamos como protocolo orientador para coleta, sistematização e análise no estudo de caso $^{9}$, compreende observar: 1) a natureza da informação (que circula em meio aos fluxos); 2) a dinâmica dos fluxos (nos quais circulam as informações); 3) o modelo de comunicação (como circulam a informações nos fluxos); 4) as práticas e dispositivos comunicativos (por que circulam nos moldes identificados pelos modelos de comunicação). Neste artigo, tratamos de apresentar apenas a síntese dos resultados que envolvem os aspectos 3 e 4 identificados nessa dimensão de estudo no Conselho Estadual de Saúde do Mato Grosso do Sul, estado da região centro-oeste brasileira.

\footnotetext{
i Em síntese, o Sistema Único de Saúde (SUS), criado pela Lei 8.080/1990, institui uma política de saúde pensada sob a ótica da integralidade, universalidade e equidade na concepção, execução e avaliação das ações de saúde. Esses princípios são potencializados pelo papel que os atores envolvidos na política de saúde assumem por meio de sua participação nos espaços para deliberar o escopo dessa política. As conferências periódicas, realizadas em âmbitos locais, estaduais e nacional reúnem um conjunto de atores para avaliarem e deliberarem a política de saúde. Os conselhos, criados por lei, e localizados em todo o território são espaços compostos pelo governo, usuários e trabalhadores de saúde para deliberarem, fiscalizarem e avaliarem as ações de saúde. Institucionalmente, existem modelos de organização similares em todas as instâncias.
} 


\section{Comunicação e informação no rito deliberativo do Conselho Estadual de Saúde do Mato Grosso do Sul}

$\mathrm{Na}$ análise organizada com base no modelo para o estudo, procura-se relacionar, conforme apontamos, as categorias analíticas reunidas em três elementos centrais para subsidiar a leitura do caso (fluxo, dinâmica informativa e modelo de comunicação) com o campo da comunicação pública e os critérios de democratização para pensar a relação constitutiva das políticas de comunicação com o controle social da política de saúde.

O espaço escolhido para estudo do caso, o Conselho Estadual de Saúde do Mato Grosso do Sul (CES/MS), foi criado em 1991, tendo como marco legal a Constituição Estadual (1989). Historicamente, o conselho é criado pouco depois das negociações em torno da Lei Orgânica da Saúde, aprovada em 1990.

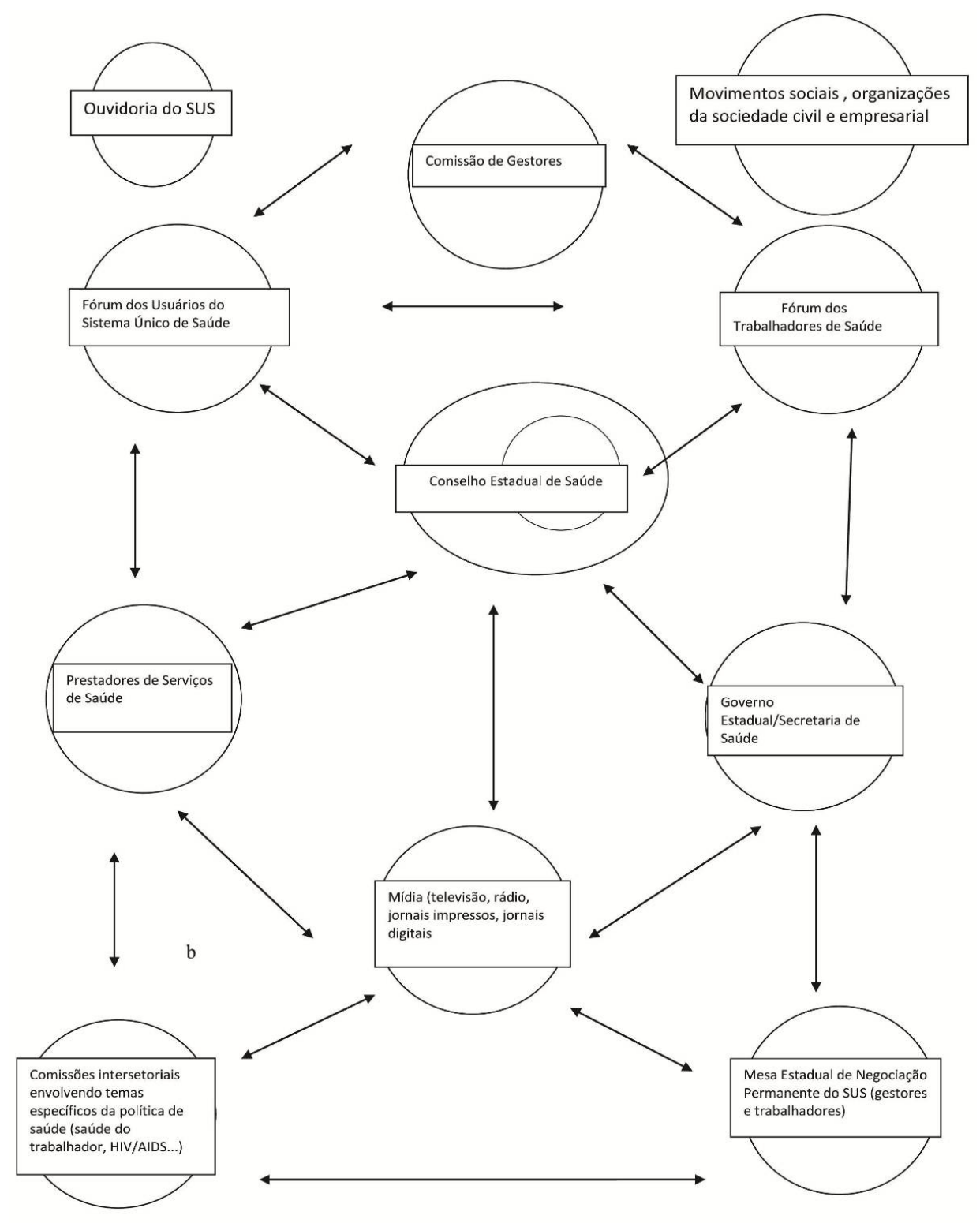

Figura 1 - Conselho em interface com suas redes Fonte: Sardinha (2011)

O entendimento que estrutura o modelo de análise aponta que o processo de deliberação nos espaços de participação, como os conselhos gestores de políticas públicas de saúde, estabelece vínculo estrutural com 
práticas e dispositivos (mecanismos estrategicamente orientados) identificados em políticas (instituídas ou não) de gestão da informação e da comunicação no interior dos próprios conselhos.

Em síntese, a disponibilidade, o modo de circulação da informação e os modelos que organizam as regras e os espaços para comunicação implicam constitutivamente no cotidiano institucional dos conselhos pela dimensão cognitiva ${ }^{10-11}$, associada à apropriação simbólica de recursos ${ }^{12}$, consubstanciada em uma dimensão comunicativa. ${ }^{13}$

É no campo simbólico e discursivo que a comunicação atua menos como instância acessória e instrumental ${ }^{14-15} \mathrm{e}$ mais como instância constitutiva em meio a disputas por poder e sentido que caracterizam o processo decisório nos espaços públicos do conselho gestor de políticas públicas.

No entanto, a primeira compreensão - predominante - entre os conselheiros de saúde entrevistados ${ }^{\mathrm{ii}}$ é da comunicação como instância assessora do colegiado, o que reforça uma vertente utilitária e instrumental a ela atribuída. Internamente, a comunicação $o^{i i i}$ exerce o papel de atuar como instância para fazer circular informações entre comissões, mesa diretora e secretaria executiva. Externamente, ela teria como função difundir informações e dar publicidade às atividades do conselho, conforme prioridades elencadas e mantidas no plano de ação para essa área. De acordo com alguns conselheiros entrevistados:

Ela [a comissão de comunicação] funciona entre aspas. Ela tem que fazer um trabalho muito amplo. Tem que divulgar tudo que sair do conselho, tem que estar à frente de todos os eventos, divulgando-os. Nós temos agora a resolução 333 do Conselho Nacional [de saúde] que vai entrar em consulta pública a qualquer momento. Qual seria o papel dessa comissão de comunicação? Teria que fazer uma articulação de comunicação com todos os conselhos deste estado [...] para a gente fazer um debate no estado dando conhecimento, levando informação, porque nem todo mundo sabe [...] As demandas do conselho, as deliberações do conselho, essa comissão teria que informar aos outros conselheiros do estado. Não é interessante que só fique aqui. Então, essa comissão teria esse papel fundamental, estaria mandando para a imprensa. Você vê alguma coisa do conselho na imprensa? (conselheiro A)

Acho que a comissão de comunicação tem a fundamental importância de ligar os elos da conferência, porque são varias comissões. Então acho que a comissão das comunicações, o próprio ato de comunicar, através da fala ou da escrita, é quando você aproxima as pessoas. Quanto mais pró-ativa ela for, mais as pessoas estarão sendo aproximadas, mais as pessoas estarão interagindo, mais as pessoas estarão escolhendo informação. (conselheiro B)

Portanto, quando se compara a comissão de comunicação e eventos com as demais comissões, no que diz respeito à atribuição de assessorar o plenário, a compreensão é de que a comunicação é um instrumento que pode atuar no estabelecimento de relações, aproximando comissões, 'estabelecendo pontes'. Na lógica da fluidez, essa perspectiva aponta para a garantia de acesso aos fatos que acontecem e que, pela estrutura de organização do conselho, acabam restritos aos espaços nos quais o conselho foi divido internamente.

O entendimento sobre o sentido que as práticas comunicativas assumem em um contexto de participação, mesmo que compreendidas 'informacionalmente' como meios para transferência de dados e informações, acaba restrito, na concepção dos conselheiros, a potencialidades suplementares das trocas informativas. A associação do acesso às informações e dos modos como são comunicadas não estão posicionados no

\footnotetext{
ii As entrevistas, como método no estudo de caso, foram realizadas com doze conselheiros, dos três segmentos integrantes do conselho e com a secretária executiva do colegiado do período (2010-2011).

iii Ao se referirem à comunicação, os conselheiros associam-na a um canal de transferência para circulação de dados e informações em uma nítida relação da comunicação como instância de suporte tecnicamente facilitadora de processos que estão à margem desses mesmos processos desencadeados no interior do jogo deliberativo. É importante registrar que três conselheiros apontaram que não pensaram em outro papel da comissão no contexto do colegiado para além das tradicionais atividades de organização de eventos, passando a pensar no assunto a partir da entrevista.
} 
discurso dos conselheiros de forma explícita, ao pontuarem as disputas entre forças e interesses que permeiam o processo decisório.

O acesso a informações é um discurso genérico e contraditório, que não aponta para uma preocupação e/ou avaliação sobre qual é o tipo e a natureza de informação que pode realmente interferir nas disputas em torno do processo decisório. Nesse caso específico, está presente a crença de que a garantia dos mecanismos de acesso à informação, com a institucionalização de fluxos e exposição dos usuários "via condutos informativos ${ }^{14}$ produziriam por si só a participação e o poder de interferência.

A busca de informação atende a uma demanda política capaz de oferecer uma distinção fundamental entre informar-se para fins de esclarecimento, evitando falas equivocadas, e a busca orientada para formatar discursos e disputar, por meio de argumentos, as decisões no colegiado (concepção pouco evidenciada pelos conselheiros nas considerações sobre o papel da comunicação no espaço do conselho).

Nos discursos abaixo encontram-se duas representações distintas, mas significativas desses dois entendimentos acima, com destaque para a predominância - entre os conselheiros entrevistados - do primeiro discurso em detrimento do segundo.

Você tem o site do Ministério da Saúde, quando você quer focar uma coisa mais específica, a fonte existe. O que você tem que ter é um pouquinho de boa vontade e procurar [...] hoje se falou sobre sistemas de médico de urgência ... na verdade é sistema móvel de urgência. Falou-se que não está nem implantado e as pessoas vieram arguir o conselho estadual. Por quê? Porque não foram beber direto na fonte. Porque se tivessem feito o caminho certo, com seus ofícios, com seus requerimentos, nós não teríamos essa discussão que é inócua, porque não existe o serviço. (conselheiro B)

Hoje a administração pública, com a política da transparência, isso [informação pública] está disponibilizado. Talvez a diferença entre eu ser da máquina, do governo, seja o conhecimento que tenho dos caminhos [...] para chegar aos dados. Além de chegar aos dados, eu também tenho o conhecimento do que eu estou procurando, é diferente. (conselheiro C)

A informação e a comunicação como vetores estruturantes (e não acessórios) para o exercício do poder em torno das disputas na definição da política de saúde acabam substituídas pelos seus papéis pedagógicos e pela capacidade de aproximação que cumprem aos conselheiros, pulverizando a dimensão política que a apropriação de informações (e não apenas o acesso a elas) e a possibilidade de agregar sentido aos dados (com estratégias para tal) têm na organização dos discursos que subsidiam o processo deliberativo.

Essa constatação está presente de modo explícito nas discussões temáticas realizadas como parte do rito deliberativo apontado acima. Os questionamentos que se seguem após as apresentações suprimem as possibilidades de debates porque o tempo dedicado a esclarecimentos e pedidos de informações genéricas, como as que versam sobre estrutura e número de atendimentos ou regras de funcionamento (disponíveis em relatórios de acesso fácil), é superior a perguntas e debates que problematizam os dados apresentados a partir de uma leitura contextual das informações.

Essa é a outra função que apontamos como uma segunda modalidade de compreensão da comunicação no conselho de saúde, identificada no discurso de um número reduzido dos conselheiros entrevistados. É um entendimento que se aproxima da dimensão cognitiva que associa a comunicação à distribuição de recursos simbólicos que impactam na participação e na agilidade para decidir.

Não tem como você discutir se você não tiver conhecimento. Porque mesmo que o meu município não tenha uma política específica estruturada, existe a política nacional, que já está estruturada. E eu tenho que conhecer ela. Senão eu não consigo discutir. Posso até discutir, mas vou fazer como alguns conselheiros que a gente tem, que falam duas horas para falar duas palavras no final. Porque ele vai 
procurando, procurando, procurando as palavras e não chega no objetivo. Quando você conhece a política, quando você busca, você não precisa impor para o gestor. Porque o que às vezes as pessoas não entendem - tem gente que fica contra a gente no conselho, é até engraçado -, é quando você consegue convencer as pessoas que você está certo. Mostrando na legislação, no regimento que você está sendo coerente. Ao invés das pessoas falarem "poxa, legal, eu aprendi!”, não. Elas ficam contra a gente. Os próprios colegas conselheiros. Acham que você está querendo se sobressair, aparecer. (conselheira D)

O conselheiro Anísio Guilherme pontua que geralmente as apresentações são muito técnicas, dificultando entendimento; diante disso, acredita que uma reunião para melhores esclarecimentos seria pertinente. O conselheiro Luis Mandetta diz que as informações que envolvem muitos números, como é o caso do Sispacto [...], os números podem dar uma série de impressões equivocadas; por este motivo, casa haja uma reunião extraordinária, seria interessante que o documento passasse primeiramente pela comissão técnica para fazer uma filtragem, qualificando os números e fazendo uma crítica prévia para depois fazer uma discussão maioriv ${ }^{\text {. }}$

Nos apontamentos envolvendo a percepção dos conselheiros sobre a capacidade que tem o Conselho Nacional de Saúde de influenciar as políticas públicas de saúde, Souza ${ }^{16}$ revela que o conhecimento de temas ligados ao campo da saúde, embora considerado um recurso de poder do colegiado por parte dos próprios conselheiros, tem uma influência relativamente menor no processo de elaboração das políticas públicas, em um contexto em que a ação política e os interesses privados influenciam de forma predominante a elaboração e avaliação das políticas públicas em detrimento de outros fatores.

Em um cenário como o apresentado por uma conselheira estadual de saúde essa constatação ganha sentido.

A maioria está hoje conselheiro - isso é uma verdade, é no país isso, não é só aqui - é como se fosse uma troca. Uma banana a troco de um cacho. Muitas pessoas vêm com muito interesse pessoal. Um é porque está almejando um trabalho na secretaria, outro porque está almejando um recurso para a sua ONG, e vai trocando. Aí, quando vai fazer intervenção, não pode. Se sente preso. Diferente de mim. Eu não tenho... muitas vezes eu falo bastante, eu discuto e até me torno sozinha no debate por conta dessas questões assim. Então é meio complicado. (conselheira A)

Já as preocupações identificadas por Souza ${ }^{16}$, envolvendo a comunicação no Conselho Nacional de Saúde, são compatíveis com a compreensão predominante entre conselheiros estaduais de saúde entrevistados, em que o papel da comunicação está mais na esfera de relação do conselho com a comunidade externa. $\mathrm{O}$ pouco conhecimento, por parte da sociedade, sobre o trabalho do conselho, e a ausência de estratégias de comunicação para aproximação dos cidadãos compõem as questões relativas à comunicação pautadas no contexto decisório da política de saúde.

Do ponto de vista da comunicação, as questões epistemológicas envolvendo a consolidação desse campo na matriz informacional ${ }^{17}$ e a reiterada confusão entre informar e comunicar, apontadas em Wolton ${ }^{7,18}$, potencializadas no imaginário de fluidez na configurada Sociedade da Informação ${ }^{19}$, corroboram para essa perspectiva instrumental e acessória atribuída ao campo da comunicação e compartilhada por atores de um espaço político em que as disputas são simbólicas e os embates discursivos.

A diferença entre acesso e apropriação, posse e uso da informação no contexto deliberativo quando mediadas por dispositivos técnicos acabam potencializando essa confusão normativa e criando, na disponibilidade e divulgação de dados, um elemento estruturalmente estratégico para organizar o processo decisório sob essa matriz que entendemos como informacional.

iv Ata pública da $231^{a}$ reunião ordinária, 2009. 
O depoimento de uma conselheira, que registramos como exceção diante dos demais conselheiros, revela a dimensão de como essa perspectiva informacional para a comunicação afeta sobremaneira a condição de uma ambiência deliberativa, fundamental para garantir o que o processo de decisão tem de mais central, a proposição e as disputas por meio do debate.

Não, não tenho [facilidade de acesso à informação pública]. É tudo muito complicado, é muito difícil o acesso. Eles falam às vezes para a gente que "Tá no site", mas nem sempre conseguimos acionar o site. Quando consegue acionar, você não consegue abrir. Quando você consegue abrir, a informação é muito velha. Isso atrapalha porque a gente leva uma vida muito corrida. Quando você tem dificuldade de acesso, você tem dificuldade de absorver. Quando você tem dificuldade de absorver você tem dificuldade de transmitir. (conselheira E)

No contorno de atuação assumido pelos conselhos gestores de saúde, em que a participação nos conselhos exacerba o papel de vigilância do conselheiro em relação ao sistema de saúde, ao invés de estímulo a uma intervenção eficaz e cidadã nos debates e construção de consensos ${ }^{12}$, essa ambiência informacional confere o ritmo ao que se tem definido como processo decisório na política de saúde.

Essa dimensão fiscalizadora se transforma em uma excessiva preocupação com o controle burocrático e administrativo das secretarias de saúde, o que negligencia questões macros ou essenciais das políticas públicas como debates sobre planos, programas, prioridades da área e resultados alcançados. ${ }^{12}$

Por essa via, a capacidade executiva de fiscalizar ao se sobrepor ao aspecto decisório e propositivo limitação de muitos conselhos gestores de políticas públicas conforme aponta Tatagiba ${ }^{20}$ - tem relação umbilical com essa construção realizada e institucionalizada sobre a comunicação, em detrimento de uma pontuação com as assimetrias simbólicas e cognitivas e, por consequência, comunicativas inerentes (e não acessórias) ao processo deliberativo como o discurso nos leva a crer.

Ao mesmo tempo, o discurso que supervaloriza a dimensão difusionista, fundamentada na ideia de que as estruturas e canais de comunicação, ao permitirem o acesso a informações e dados significativos, produzem nova participação, atrelando a informação à sua natureza quantitativa, estabelece vínculo com essa exacerbação do controle como matriz central para pensar o controle social em saúde.

Essa perspectiva ajuda a compreender o discurso da transparência e do direito à informação restrito à disponibilização de dados e à dificuldade de se perceber que, assim como o silêncio define a posição dos conselheiros no processo deliberativo, o superávit de informações pode desfavorecer um debate provocativo pela ausência de dados qualificados.

Veja hoje, a discussão dentro do conselho, quando você vai fazer realmente uma discussão para controlar alguma atividade, alguma ação, o foco dos conselheiros é na assistência. Eles têm o fim. Eles focam exatamente naquela ação. É a sinalização, é a pouca noção da política pública como um todo, da forma de organização da política, do planejamento, da parte do financiamento, da própria execução da política. Então, esse desconhecimento é do sistema como um todo - não é do sistema de saúde, é do sistema público, da política pública, do financiamento da política pública. [...] Acho que ele precisa começar a entender o sistema da porta do consultório até as conferências, até os planejamentos, o PPA [Plano Plurianual], em uma política macro, em uma lei orçamentária... os instrumentos de financiamento. Acho que falta muito. Acho que isso é a grande base para deliberar mesmo o controle e fazer realmente controle da política. O segmento que ali é representado fica com pouca atuação, com pouca força de definir realmente uma mudança, porque ele não tem essa condição. Ele acaba sendo levado a pensar aquele problema de uma forma que acaba fazendo com que ele vá junto com uma forma que já estava 
estabelecida. Então o controle não se faz. [...] Mas a gente vê esse jogo de uma forma que o próprio conselheiro não consegue perceber a não atuação naquele momento. A participação dele acaba sendo quase inócua. (conselheira $C$ )

Nessa perspectiva, o discurso do acesso irrestrito e fácil a dados e informações pode ser relativizado por não impedir que as deliberações sejam formatadas pelo discurso pragmático que supervaloriza os resultados das ações em saúde (o lado finalístico e pontual da política) em detrimento de aspectos mais centrais e estruturais (processos políticos, normativos e conceituais) envolvendo a política pública.

A situação é representativa na discussão registrada em ata de reunião ordinária do conselho sobre um programa de ações na área de saneamento ambiental com financiamento do governo federal e contrapartidas do governo do estado com necessidade de aprovação por deliberação do conselho estadual. A deliberação por ad referedum tomada pela autoridade competente, no caso específico, pela presidência do conselho, sem participação dos demais conselheiros, foi colocada em discussão na reunião ordinária para ser referendada pelo plenário, que é a instância máxima de deliberação do conselho.

O Conselheiro João Batista Botelho fala que no documento que recebeu, só apresenta valores, não há exemplo de como o Projeto procede e como será feita a execução destes trabalhos. O Conselheiro pergunta se há contrapartida. Coloca que o CES (Conselho Estadual de Saúde) não pode aprovar projetos no afogadilho, afinal o valor do Projeto é de $R \$ 60.000 .000,00$ (sessenta milhões de reais). Outra questão é com relação à emenda constitucional $N^{o} .29$ que define o que é investimento em saúde e o que não é. Há muito tempo, briga, dizendo que saneamento e abastecimento de água não são considerados investimentos em saúde. [....] O Conselheiro Luíz Henrique Mandetta diz que é muito claro o ritmo e a velocidade, pelo próprio nome do Programa "Aceleração do Crescimento". O Programa veio de cima para baixo. Não cabe agora, neste momento de escassez de investimento neste tipo de infraestrutura, questionar se ela vai fazer uso político ou não. O Governo do Estado está entrando com o recurso e logicamente para entrar com estes recursos fez a análise do Projeto, caso contrário não teria investido recurso. Entende 10o\% a atitude do Coordenador da Mesa Diretora quando este deu o Ad Referendum sobre o Programa. Com certeza a Funasa [Fundação Nacional de Saúde] aguarda este documento para dar sequência no Projeto. Sugere a confirmação do Ad Referendum condicionada à apresentação passo a passo do Programa. [...] Presidente Fernando de Oliveira Rocha fica decidido que a Comissão de Serviço de Saúde analise o Ad Referendum e que na Reunião Ordinária/Descentraliza do CES que acontecerá em Nova Andradina este seja referendado ${ }^{v}$.

Esse registro é significativo quando relacionado ao entendimento de que democracia deliberativa não se traduz necessariamente na democratização da participação, ao apresentar uma face excludente, considerando o prisma liberal da teoria deliberativa habermasiana13, em que o apelo ao consenso, a partir da ideia de uma racionalidade geral, distancia grupos e segmentos que entram nos espaços de decisão em desvantagem para decidir.

Nesse caso, o fluxo de informação oficial (unilateral) trabalha na tentativa de reduzir as questões conceituais e políticas que organizam o processo decisório com elementos pouco representativos do sentido e dimensões da política pública. Conhecimentos, experiências e concepções para qualificar o olhar para a política pública em discussão acabam suprimidos, contraditoriamente, pela quantidade elevada de dados disponíveis e com acesso facilitado.

v Ata pública da $229^{a}$ reunião ordinária, 2009. 
Cabe destacar que assimetrias cognitivas, que interferem no processo deliberativo, não têm relação com instrução e formação educacional, mas com a natureza e legitimidade de conhecimentos e formas de apropriação para construção e formatação dos discursos como meio para disputa por poder no processo deliberativo. ${ }^{10}$

É sob essa direção que está colocada outra fragilidade dos discursos utilitários para práticas comunicativas, evidenciada entre os conselheiros de saúde. São discursos que reduzem a informação, a comunicação da informação e a necessidade de sua gestão a elementos acessórios e instrumentais do contexto deliberativo.

Esses mesmos discursos legitimam, por sua vez, a compreensão publicista (de colocar em circulação, difundir) na associação pedagógica de decifrar códigos do discurso burocrático e especializado com a prática comunicativa:

[...] Um relatório de gestão, por exemplo, é super complicado, a gente não entende ele muito fácil, um plano de saúde é muito complicado, você acaba não entendendo. Aí fica difícil por causa disso. [...] Por exemplo, siglas. Muitas vezes o documento chega cheio de siglas que a gente não tem a mínima ideia do que é aquilo. A comunicação faria essa ponte, de desmembrar para a gente o que significam aquelas siglas. (conselheira E)

Adiantamos que a questão cognitiva envolvendo a comunicação no processo deliberativo, no entanto, não está sendo lida sob a ótica da interpretação e decodificação, de acordo com a compreensão compartilhada pela maioria dos conselheiros. Essa perspectiva instrumentaliza de modo muito similar a comunicação e a informação nos reduzidos papéis de canais para transferência de um polo a outro.

Se a preocupação central da deliberação, nos moldes apontados em Silveirinha ${ }^{13}$, é com a desvantagem com que grupos e representações entram na arena decisória, entendemos que essa assimetria se dá em proporções significativas em função da hegemonia de algumas fontes de legitimidade dos discursos que fundamentam e validam as decisões em detrimento de outras fontes de legitimidade.

No caso específico do conselho de saúde identificamos o discurso da competência, o discurso técnicoespecializado e o discurso oficial - presentes e reafirmados na natureza e na dinâmica dos fluxos disponíveis no interior da arena decisória do conselho - como legítimos para enquadrar e organizar o rito deliberativo, em detrimento do discurso da experiência e do discurso não especializado e competente.

A dimensão cognitiva e simbólica relacionada à apropriação de informação e ao modelo de comunicação responsável pela gestão de seus fluxos está atrelada, portanto, a condições de produção dos discursos que serão disputados no contexto deliberativo. E, nesse sentido, o investimento na redução das assimetrias, na perspectiva da comunicação pública, requer o estímulo aos conflitos e embates entre as instâncias de produção e reconhecimento dos discursos ${ }^{21}$ que permeiam o rito deliberativo. As assimetrias nessas duas instâncias é o que garante (ou não) a dimensão pública ao processo decisório e não apenas às decisões. ${ }^{13}$

A perspectiva transferencial e acessória que restringe o campo da comunicação à atuação em uma instância de circulação de informações (a do publicizar, difundir) trabalha sob essa ótica para aprofundar as distâncias, na medida em que não atua nas fontes de produção e reconhecimento dos discursos que produzem sentido e formatam as decisões.

Sob esses moldes, o consenso como produto deliberativo torna-se fonte de legitimação pouco pública para o que é decidido, mesmo que sob os moldes da abertura democrática à participação. As disputas em torno da informação e do modo de comunicá-las acontecem, portanto, nas respectivas instâncias produtoras de sentido (em uma dimensão ideológica) e de reconhecimento (em uma dimensão de poder).

Silva $^{22}$ identifica quatro dimensões fundamentais à compreensão e explicação das experiências participativas, a partir das investigações realizadas. A primeira é a dimensão associativa, relacionada à forma como são constituídas as organizações sociais, seus padrões organizativos, os discursos que mobilizam para 
sua ação, conflitos, relações de poder e identidades coletivas nas quais se inserem, entre outras questões. A segunda é a dimensão que aborda a cultura e práticas de atores políticos, funcionamento das instituições políticas, aliança, diretrizes, estratégias e tipos de organização dos atores políticos. A terceira é a dimensão institucional e enfoca as condições institucionais que a constituem e nas quais se desenvolvem os processos políticos, regras, valores, cultura e prática de agentes institucionais. E, por fim, a dimensão socioeconômica, que trata de aspectos referentes aos padrões e mecanismos de distribuição da riqueza, condições de acesso a bens e serviços públicos, formas de distribuição e ocupação dos territórios entre outros.

Nesse sentido, considerando as dimensões que envolvem o processo deliberativo apontadas em contexto de autoritarismo social, hierárquico e excludente da sociedade e da política apontado em Dagnino ${ }^{23}$, observados sob a ótica da comunicação, os conselhos podem ser restritivos à participação, potencializando um discurso participativo de democracia direta tão regulador e restritivo quanto os espaços políticos representativos.

É interessante observar nos depoimentos dos conselheiros como as assimetrias são percebidas e interpretadas a partir das especificidades de cada um dos segmentos, a saber: gestor, trabalhador e usuário do Sistema Único de Saúde (SUS), respectivamente.

O nosso sistema público, nossa administração pública, é muito complicada. Isso não é um conhecimento difuso, um conhecimento empírico para as pessoas. Isso exige conhecimento técnico, educação continuada. Então a gente tem ali um segmento de pessoas, da sociedade, que não faz parte do cotidiano deles. As pessoas dizem que é porque a gente é uma democracia muito recente, então o controle social ainda não consegue ter o alcance da ação do Estado para poder avaliar. Não sei quanto tempo a gente demoraria para que as pessoas da nossa sociedade, para que o cidadão que é realmente o beneficiário daquele serviço, ele consiga ter o entendimento de todo esse arcabouço jurídico, legal, institucional, que é muito complicado. (conselheira $C)[. .$.$] Nós sabemos que esse país é um país com diferenças extremamente$ abissais. Nós temos aqui no nosso plenário pessoas que têm segundo grau, pessoas que têm primeiro grau, temos pessoas de quem a escolaridade é mínima, temos mestres, temos doutores... Isso é o que faz o debate se tornar interessante. Porque nós pegamos das coisas mais simples que às vezes não afligem um doutor, que consegue ver a sociedade com uma amplitude maior. E isso vai dando um equilíbrio. Então sobre o SUS, o debate consegue se complementar porque nós temos essas opiniões extremamente distintas. (conselheira $B$ )

Os conselheiros têm dificuldade de participar do debate dentro do conselho por conta de que é muita coisa para ler, na maioria das vezes as pessoas têm muita dificuldade de ler, por qualquer motivo: por ter pouca leitura, por pouco tempo... Um documento às vezes é muito complicado. [...] A gente geralmente consulta outros colegas. Ouve outras opiniões e pergunta para outros colegas e passa para os outros colegas a opinião da gente, e a gente faz essa discussão entre a gente, entre os conselheiros. [...] Geralmente, quando você vai discutir um tema, você recebe antes a documentação do que vai ser discutido naquilo. Então você tem que discutir aquele assunto, você tem que estudar aquele assunto. Porque muitas vezes uma decisão não serve para outra. [...] Às vezes eu leio o documento e se eu não entender, eu pergunto para outro. Às vezes nem especificamente outro do próprio segmento, mas outra pessoa que está dentro do processo e que sabe o que é. (conselheira E)

Nesse contexto, a comunicação atua em uma perspectiva na qual a dimensão funcional ${ }^{18}$, representada na lógica transferencial e acessória ${ }^{14}$, tem dificuldade de ser posicionada no que configuramos como vertente constitutiva. Em uma abordagem conceitual, não há significados a serem decodificados em um processo de decisão, mas sentidos e saberes (técnicos, políticos e cotidianos/experienciados) que se conflitam em 
meio aos discursos que se constroem e circulam na esfera pública especializada do conselho, permeada por inúmeras outras esferas públicas que orbitam em torno do colegiado.

Os sentidos constroem-se por meio de um complexo processo de semiose social envolvendo investimento de tempo-espaço sob a forma de discursos produzidos a partir de uma gramática de produção (ideologia) e outra de reconhecimento de sentido (poder) permeada de circulação. ${ }^{21} \mathrm{O}$ diálogo, portanto, como substrato para a deliberação, ao invés de orientar (e ser orientado) para o entendimento ou consenso pelos recursos da ação racional (a partir da tentativa de decifrar códigos), torna-se um espaço de disputa por sentidos em um cenário marcado por relações de visibilizar-invisibilizar discursos, saberes, informação e conhecimento. ${ }^{45}$

Nesse contexto, o discurso mais eficaz não é exclusivamente aquele organizado sobre a lógica da racionalidade técnica e comunicado sob a perspectiva do discurso competente. ${ }^{24}$ Ao contrário, é o que se legitima e é representativo da localização social dos interlocutores e de acordo com as competências culturais, simbólicas e políticas de que são portadores. ${ }^{12}$

Para Oliveira' ${ }^{12}$, essas variáveis explicitam o elo entre ação, significado da ação e as relações sociais. Portanto, o poder de um dado discurso está nessa relação operada constitutivamente pela comunicação como instância produtora de sentidos, e não como instrumento para circulação de informações e criação da ambiência dialógica.

Sendo assim, a circulação de e o acesso a informações que se organizam em um modelo de comunicação em fluxos unidirecionais, que ora difundem/publicizam sob a lógica da decodificação, operam como eficazes dispositivos de poder, em meio ao processo de deliberação, diante do cenário de assimetrias e da gestão informativa que está condicionada ao rito deliberativo - identificado e organizado na estrutura de cada conselho.

No caso específico do controle social das políticas de saúde, a criação de esferas públicas amplas a partir divulgação de questões envolvendo o conselho de saúde ou com a criação de canais para facilitar a circulação interna de dados e informação, como apoiar e legitimar o processo decisório na vertente do modelo informacionalista para o processo de comunicação $0^{7,18}$, significam, no contexto de assimetrias e desigualdades inerentes ao processo deliberativo, tornar a participação um processo homologatório de decisões previsíveis na disputa por sentido do melhor discurso. Essa situação, como dissemos, é apontada nos estudos sobre a eficácia deliberativa dos conselhos gestores. ${ }^{20}$

Nessa matriz informacional que opera a dinâmica comunicativa dos conselhos, o discurso da competência acaba reconhecido e legitimado pela circulação eficaz dos que detêm o poder, por possuírem o maior número de meios à disposição (quantidade), ou os mais raros e escassos (exclusividade) ou o meio de maior valor importância. ${ }^{22}$

É por essa via que, mesmo como um dispositivo acessório, a gestão dos processos de produção, circulação, sistematização e difusão de informação, quando feita sob a ótica de fluxos legitimadores e legitimados pelos discursos oficiais - os discursos competentes e os discursos técnicos e especializados e orientados pelo paradigma transferencial de pensar a comunicação - torna-se espinha dorsal do processo decisório, sendo capaz, inclusive, de transformar questões pontuais em gerais, interesses particulares em públicos, privilegiando determinadas vias de compreensão em detrimento de outras.

Essas estratégias, por sua vez, privilegiam o jogo de poder, ao invés do poder do jogo, na expressão de $\mathrm{Matos}^{25}$, para avaliar o significado da comunicação pública, que apontamos como campo central no contexto da democracia deliberativa, em um contraponto conceitual sobre a comunicação política. O entendimento baseado em Bourdieu ${ }^{26}$ é de que as relações de comunicação são inseparáveis de relações de poder, dependentes, por sua vez, do poder material ou simbólico acumulado pelos agentes dessas mesmas relações. A apropriação e o controle dos dispositivos - que permitem circulação de informação e construção de legitimidade para alguns modos de comunicar os sentidos que permeiam o processo deliberativo demonstram a operação do poder de constituir o dado pela enunciação, o dito poder simbólico, em que as palavras (de ordem) organizam as formas de fazer ver e fazer crer, de confirmar ou transformar a visão de 
mundo, a partir de uma crença da legitimidade do que se fala e de quem fala, conforme aponta o próprio Bourdieu. ${ }^{26}$ Por essa via, o jogo de poder é simbólico na medida em que o monopólio e a hegemonia dos discursos válidos para a deliberação incorporam a dimensão técnica e burocrática envolvendo a política pública de saúde, desconsiderando outros discursos, experiências e dizeres secundários em uma hierarquia construída, a partir desse capital político objetivado em práticas e protocolos comunicativos que dão suporte à construção do poder deliberativo de uns atores sobre outros.

O jogo de poder, operado pela lógica informativa e comunicacional contribui, nesse sentido, para que os conselhos não só se tornem espaços pouco propositivos, no que se refere à capacidade de incidir na formulação de políticas públicas, mas também à possibilidade de democratização de suas práticas políticas², reproduzindo e reafirmando novamente lógicas criticáveis nos processos políticos majoritários, sintetizados no depoimento da conselheira estadual de saúde.

O estado (governo do estado) está montando o plano que tem que ser aprovado esse ano. Eu faço parte da comissão de plano e nós não temos nada ainda. Nós não recebemos nada, nada como conselho. Então há muita falta de tempo para discutir, há muita demora do gestor em repassar o material. Porque a gente tem prazo. (Já) o relatório de gestão que a gente fala é o relatório das atividades do ano, dos gestores. Terminou o ano 2010, tem que estar com o relatório pronto. Até maio tem que estar aprovado. Se não aprovar pelo conselho o relatório de gestão, ele não recebe verba. É o critério do Ministério da Saúde. O que acontece? Quando chega no início de abril, ainda não chegou o relatório. Aí quando mandam, mandam correndo. Tem que ter duas ou três reuniões extraordinárias para você discutir aquilo, apesar de que o relatório já foi, você não vai mudá-lo. Mas tem que ter clareza do que está aprovando e tem que estar comprovado que o que estava ali no plano foi cumprido. Então você não consegue analisar. [...] E no dia 30 de maio, que é a nossa reunião, nós temos que aprovar. E, para aprovar, a gente tem que estar dez dias antes com o parecer pronto. E não sei se nós vamos conseguir, mas tem essa questão. Em um relatório de gestão ainda é uma coisa que já foi. Agora quando é um plano, outras pautas, plano de política para adolescentes, muitas vezes vem tudo correndo. (conselheira D)

\section{Considerações finais}

A dimensão funcional que restringe o processo de comunicação à transmissão de dados hegemonicamente se sobrepõe à dimensão normativa da comunicação, espaço de coabitação e dispositivo que visa amortecer o encontro de várias lógicas que coexistem na sociedade aberta. ${ }^{7}$ Essa dimensão normativa, em contraponto à dimensão funcional, confere à comunicação um papel de organização simbólica, mais do que um canal, em meio à profusão técnica de transmissão de dados e informação.

É nessa terceira etapa da relação informação-comunicação que a comunicação pública relaciona-se com a gestão do poder político em sociedades democráticas, oferecendo as condições para garantir a dimensão normativa da comunicação e de sua relação (constitutiva) com o processo deliberativo nos moldes críticos que estamos apresentando.

Essa abordagem torna-se o horizonte da comunicação e, por conseguinte, da democracia, por presumir a organização do poder e da autoridade pela negociação e pelo debate. Nesse sentido, a comunicação deixa de ser uma mera solução, tornando-se um problema a ser administrado pelas vias da incomunicação ${ }^{7}$, das tensões e do conflito que não estão previstos na exacerbação estratégica da dimensão funcional. Menos que um dispositivo técnico, a comunicação torna-se a condição para simbolização, responsável pelo funcionamento das sociedades democráticas, sobretudo diante das demandas cada vez mais complexas colocadas aos Estados e às democracias. 
Das pontuações conceituais e empíricas proporcionadas nesta primeira análise dos dados coletados no presente estudo, entendemos que, quando impossibilitada a comunicação (em função das assimetrias), o que predomina na arena dos conselhos de saúde é uma situação de permanente não comunicação, fazendo com que, segundo Oliveira ${ }^{12}$, a reciprocidade de atos e palavras tenha pouca consistência na determinação das políticas de saúde, prevalecendo verticalmente algumas vozes como instância de poder em detrimento de outras.

Como constitutiva do processo deliberativo, portanto, a comunicação não é uma correia de transmissão organizando funcionalmente o espaço, as regras e o procedimento deliberativo, calcado em uma ação orientada, por sua vez, pela racionalidade comunicativa. Ao consideramos as desigualdades de acesso à esfera pública deliberativa pelos desequilíbrios na apropriação dos recursos cognitivos, as ações e estratégias de comunicação devem atuar para transformar o jogo de poder em poder para o jogo ${ }^{25}$, em uma dimensão comunicacional da democracia que realça o conflito e a pluralidade como dinamizadores de esferas públicas democráticas. Levando em conta que a concentração do capital político está diretamente relacionada a instrumentos materiais e culturais fundamentais para ativar a participação política, a comunicação como política pública é elemento central para a disputa por sentidos nesse contexto. E, nesse âmbito, é importante aprofundarmos o debate sobre políticas e ações estratégicas de comunicação para as políticas públicas.

\section{Referências}

1. Sardinha AC. Comunicação pública e participação nos conselhos gestores de políticas públicas: um estudo de caso do conselho estadual de saúde de Mato Grosso do Sul [dissertação]. São Paulo: Programa de Pós-graduação em Comunicação, Universidade Estadual Paulista Júlio de Mesquita Filho; 2011.

2. Raichelis R. Esfera pública e conselhos de assistência social. São Paulo: Cortez; 1998.

3. Moreira MR, Castro EV. A democratização nos conselhos de saúde. Saúde Debate. 2006 maio/ dez.;30(73/74):205-18.

4. Pitta AMR. Interrogando os campos da saúde e da comunicação: notas para o debate. In: Pitta AMR, organizadora. Saúde e comunicação: visibilidades e silêncios. Rio de Janeiro: Hucitec Abrasco; 1995; p. 239-66.

5. Pitta AMR. Comunicação, promoção da saúde e democracia: políticas e estratégias de comunicação no Sistema Único de Saúde no Brasil [tese]. Rio de Janeiro: Programa de Pós-Graduação em Comunicação, Universidade Federal do Rio de Janeiro; 2001.

6. Monteiro GF. A singularidade da comunicação pública. In: Duarte J, organizador. Comunicação pública: estado, mercado, sociedade e interesse público. São Paulo: Atlas; 2009. p. 34-46.

7. Wolton D. É preciso salvar a comunicação. São Paulo: Paulus; 2006.

8. Duarte MYM. Estudo de caso. In: Duarte J, Barros A, organizadores. Métodos e técnicas de pesquisa em comunicação. São Paulo: Atlas; 2006. p. 215-35.

9. Sardinha AC. Comunicação e saúde: contribuições teóricas e metodológicas para o estudo de políticas de comunicação nos espaços decisórios dos conselhos gestores de saúde. Extrapensa. 2013;2:147-71.

10. Correia JC. Ideologia, crítica e deliberação. In: Correia JC, Ferreira GB, Espirito Santo P, organizadores. Conceitos de comunicação política. Covillhã: Labcom Books; 2010. p. 9-20.

11. Gomes W. Esfera pública política (parte I). In: Gomes W, Maia RCM. Comunicação e democracia: problemas e perspectivas. São Paulo: Paulus; 2008. p. 29-162.

12. Oliveira VC. Desafios e contradições comunicacionais nos conselhos de saúde. In: Ministério da Saúde, Conselho Nacional da Saúde (Brasil). Coletânea de Comunicação e Informação em Saúde para o exercício do Controle Social. Brasília; 2006. p. 29-46.

13. Silveirinha MJ. Democracia e reconhecimento: repensar o espaço público. In: Barbalho A, Paiva R, organizadores. Comunicação e cultura das minorias. São Paulo: Paulus; 2005. p. 41-70. 
14. Fausto Neto A. Percepções acerca dos campos da saúde e da comunicação. In: Pitta AMR. Saúde e Comunicação: visibilidades e silêncios. Rio de Janeiro: Hucitec, Abrasco; 1995. p. 267-94.

15. Moraes IHS. Informação em saúde para o exercício do controle social: a luta pela democratização e qualidade da informação. In: Coletânea de Comunicação e Informação em Saúde para o exercício do Controle Social. Brasília; 2006. p. 17-28. Série F, Comunicação e Educação em Saúde).

16. Souza PH. O exercício da participação popular através do Conselho Nacional de Saúde nos anos 90 . In: Dagnino E, Pinto RP, organizadores. São Paulo: Contexto; 2007. p.47-68. (Justiça e Desenvolvimento/ IFP-FCC).

17. Pasquali A. Um breve glossário descritivo sobre comunicação e informação.In: Melo JM, Sathler $L$, organizadores. Direitos à comunicação na sociedade da informação. São Bernardo do Campo, SP: Umesp; 2005. p. 15-48.

18. Wolton D. Informar não é comunicar. Porto Alegre: Sulina; 2010.

19. Mattelart A. Sociedade do conhecimento e controle da informação e da comunicação [Internet]. In: Anais do $5^{\circ}$ Encontro Latino de Economia Política da Informação, Comunicação e Cultura; 2005 nov. 9-11; Salvador; 2005 [citado Disponível em: https://goo.gl/yCXSLH

20. Tatagiba L. Os conselhos gestores e a democratização das políticas públicas no Brasil. In: Dagnino $\mathrm{E}$, organizadora. Sociedade civil e espaços públicos no Brasil. São Paulo: Paz e Terra; 2002. p. 47-105.

21. Verón E. A produção de sentido. São Paulo: Cultrix; 1980.

22. Silva M.K. Dos objetos às relações: esboço de uma proposta teórico-metodológica para a análise dos processos de participação social no Brasil. In: Dagnino E, Tatagiba L, organizadores. Democracia, sociedade civil e participação. Chapecó (SC): Argos; 2007. p.477-497.

23. Dagnino E. Sociedade civil e espaços públicos no Brasil. In: Dagnino E, organizador. Sociedade civil e espaços públicos no Brasil. São Paulo: Paz e Terra; 2002. p. 9-16.

24. Chauí M. Cultura e democracia. São Paulo: Cortez; 2003.

25. Matos H. Comunicação pública, esfera pública e capital social. In: Duarte J, organizador. Comunicação pública: estado, mercado, sociedade e interesse público. 2 ed. São Paulo: Atlas; 2009. p. 47-58.

26. Bourdieu P. O poder simbólico. Tradução Fernando Tomaz. Lisboa: Difel; 1989. 